\title{
Single Nucleotide Polymorphisms in CD14 and Toll-like Receptor 4 Genes in Patients with Polycystic Ovarian Syndrome
}

\author{
${ }^{1}$ Nazima Allauddin, ${ }^{2}$ Roya Rozati
}

\begin{abstract}
Introduction: Polycystic ovary syndrome (PCOS) is a complex disease having genetic, immunologic, and environmental components, and candidate genes on innate immunity have been hypothesized to be involved in its etiology. We examined the possible association of CD14 and toll-like receptor 4 (TLR4) polymorphisms with PCOS.
\end{abstract}

Materials and methods: A total of 219 women with PCOS and 272 healthy women were recruited in the study. Their samples were genotyped for the polymorphism of CD14 and TLR4 genes.

Results: The distributions of genotypes of both polymorphisms were found to be significant in women with PCOS compared with controls. The distributions of alleles were also found to be predominant in PCOS compared with controls.

Conclusion: Polymorphisms in CD14-159C $>T$ and TLR4$299 A>G$ significantly increased susceptibility to PCOS. Further studies with larger sample sizes are warranted to confirm these findings.

Keywords: CD14, Polycystic ovary syndrome, Polymorphisms, Toll-like receptor 4 .

How to cite this article: Allauddin N, Rozati R. Single Nucleotide Polymorphisms in CD14 and Toll-like Receptor 4 Genes in Patients with Polycystic Ovarian Syndrome. J South Asian Feder Obst Gynae 2017;9(4):304-307.

\section{Source of support: Nil}

Conflict of interest: None

Date of received: 5 October 2017

Date of acceptance: 28 November 2017

Date of publication: January 2018

\section{INTRODUCTION}

Polycystic ovary syndrome affects about 1 in 10 women of reproductive age and is the most common endocrine condition in this group. It is a heterogeneous disease

\footnotetext{
${ }^{1}$ Assistant Professor, ${ }^{2} \mathrm{Head}$

1,2Department of Obstetrics and Gynecology, Deccan College of Medical Sciences, Hyderabad, Telangana, India

Corresponding Author: Nazima Allauddin, Assistant Professor Department of Obstetrics and Gynecology, Deccan College of Medical Sciences, Hyderabad, Telangana, India, Phone: +919550548999, e-mail: allauddinnazima@gmail.com
}

characterized by oligomenorrhea due to increased ovarian and adrenal androgen secretion, and hyperandrogenic symptoms such as hirsutism, acne, and/or alopecia. Multiple endocrinological, metabolic abnormalities and anovulation are associated with PCOS. Around $80 \%$ of women with PCOS have irregular menstrual cycles; ${ }^{1}$ many are anovulatory. ${ }^{2}$ Some patients are managing to conceive effectively after treatment, but there is a high risk of complications during pregnancy as well as neonatal complications. ${ }^{3}$ This disorder is also associated with an increased risk of hyperinsulinemia, insulin resistance, type II diabetes mellitus, dyslipidemia, and cardiovascular diseases. ${ }^{4,5}$

The etiology of PCOS is not yet clear. However, environmental, genetic, immunological, and biochemical factors are concerned with the etiopathogenesis of PCOS. ${ }^{6}$ Several candidate genes have been proposed as significant contributors to PCOS, but none have yet achieved acceptance as major cause. ${ }^{7}$ The PCOS is related with chronic inflammation, ${ }^{8}$ and genes related to innate immunity may contribute to its pathogenesis. ${ }^{9}$ To the best of our knowledge, no studies have examined the possible association of genetic variants in the genes encoding TLRs and CD14 with PCOS from India.

Several studies have shown that a polymorphism in the CD14 proximal promoter, $-159 \mathrm{C} / \mathrm{T}$ (rs2569190), might act together with environmental factors in the progress of disease. ${ }^{10}$ Previous studies have investigated whether the $-159 \mathrm{C} / \mathrm{T}$ polymorphism in the CD14 gene is associated with different disease risks and the results have been contradictory and uncertain. ${ }^{10}$

The CD14 and TLR4 are interlinked components with clearly defined roles in immunologic and inflammatory pathways. ${ }^{11}$ The TLR4 is one of the important signaling receptors of innate immunity. It determines the presence of bacterial lipopolysaccharide (LPS) associated with CD14 or MD-2 and initiates a proinflammatory signaling cascade. The classical mechanism by which LPS-induced TLR4 signaling includes activation of mitogen-activated protein kinases and nuclear factor $\mathrm{kB}$ results in secretion of proinflammatory cytokines such as tumor necrosis factor- $\alpha$, interleukin- $1 \beta$ (IL-1 $\beta$ ), IL-6, and others. ${ }^{12}$ In dendritic cells, CD14-dependent endocytosis pathway is upregulated upon exposure to inflammatory mediators. The aim of our study was to investigate the impact of 
gene (CD14 and TLR4) polymorphisms involved in the innate immune system on PCOS.

\section{MATERIALS AND METHODS}

\section{Study Population}

A total of 219 patients and 272 controls were recruited from Owaisi Hospital and Research Centre, Hyderabad, India, in the present study. Patients were recruited based on Rotterdam criteria according to which a woman is said to have PCOS if she has any two features such as polycystic ovaries on ultrasound scan and menstrual irregularities. Ultrasound-scanned normal fertile women with no menstrual dysfunction or histories of infertility were recruited as controls. Written consent was taken from all subjects. The study was approved by the Institutional Review Board, Deccan College of Medical Sciences. Detailed information on clinical, anthropometric measures and diet was recorded through pro forma. Our sample size of 491 (219 patients +272 controls) is large enough and exceeds the estimated number of samples ( 200 cases + controls) required to obtain a 90\% statistical power.

\section{Molecular Analysis}

Two milliliter of peripheral blood sample was collected from each participant. Deoxyribonucleic acid was extracted from peripheral blood samples and genotyping was done for CD14 and TLR4 genes. Genotyping of CD14-159C > T polymorphisms was performed using the tetra-primer amplification refractory mutation systempolymerase chain reaction as described previously ${ }^{13,14}$ with minor modifications (annealing temperature $59^{\circ} \mathrm{C}$ ).

Table 1: CD14 allele frequency distribution in controls and PCOS

\begin{tabular}{llllll}
\hline & \multicolumn{2}{c}{ Control } & & \multicolumn{2}{c}{ Patients } \\
\cline { 2 - 3 } Allele & Number & Frequency & & Number & Frequency \\
\hline $\mathrm{C}$ & 457 & 0.84 & & 276 & 0.63 \\
\hline $\mathrm{T}$ & 87 & 0.16 & & 162 & 0.37 \\
\hline
\end{tabular}

Polymorphism in the TLR4 (299A > G) was performed by allele-specific amplification as described previously. ${ }^{15}$ All amplifications were repeated twice and were analyzed using agarose gel electrophoresis system.

\section{Statistical Analysis}

The genotypic distribution of CD14 and TLR4 gene was performed using $\chi^{2}$ test. Distribution of genotypes and alleles between PCOS and control groups was tested using Fisher's exact test. Since differences between conditional logistical regression and unconditional logistical regression were small, unconditional logistical regression was used to estimate odds ratio (OR) and 95\% confidence interval (CI). The above statistical analysis was performed using GraphPad Prism version 5.0 (GraphPad Software, Inc., San Diego, California, USA).

\section{RESULTS}

The " $\mathrm{T}$ " allele was found to be in higher frequency in PCOS compared with controls ( 0.37 vs 0.16 , respectively; Table 1).

Heterozygote CT was found to be predominant in PCOS (0.68) when compared with controls (0.29; Table 2).

The CT genotype was found to be predominant in PCOS with 5.53-fold increased risk to PCOS when compared with wild-type genotype (CC) (OR 5.53, 95\% CI 3.73-8.20, p <0.0001). Homozygous variant was also observed to be associated with PCOS (OR 5.17, 95\% CI 1.46-18.23, $\mathrm{p}<0.0001)$. Dominant model (CT + TT) was also found to be associated with high risk to PCOS (OR 5.51, 95\% CI 3.74-8.14, p <0.0001; Table 3). Overdominant model CT (compared with CC + TT genotype) genotype

Table 2: CD14 genotypic frequency distribution in controls and PCOS

\begin{tabular}{llllll}
\hline & \multicolumn{2}{c}{ Control } & & \multicolumn{2}{c}{ Patients } \\
\cline { 2 - 3 } \cline { 5 - 6 } Genotype & Number & Frequency & & Number & Frequency \\
\hline C/C & 189 & 0.69 & & 64 & 0.29 \\
$\mathrm{C} / \mathrm{T}$ & 79 & 0.29 & & 148 & 0.68 \\
$\mathrm{~T} / \mathrm{T}$ & 4 & 0.01 & & 7 & 0.03 \\
\hline
\end{tabular}

Table 3: Odds risk estimation of the CD14 genotype in PCOS compared with controls

\begin{tabular}{|c|c|c|c|c|c|}
\hline Model & Genotype & Control & Patients & OR (95\% Cl) & $p$-value \\
\hline \multirow[t]{3}{*}{ Codominant } & $\mathrm{C} / \mathrm{C}$ & $189(69.5 \%)$ & $64(29.2 \%)$ & 1.00 & $<0.0001$ \\
\hline & $\mathrm{C} / \mathrm{T}$ & $79(29 \%)$ & $148(67.6 \%)$ & $5.53(3.73-8.20)$ & \\
\hline & $\mathrm{T} / \mathrm{T}$ & $4(1.5 \%)$ & $7(3.2 \%)$ & $5.17(1.46-18.23)$ & \\
\hline \multirow{2}{*}{ Dominant } & $\mathrm{C} / \mathrm{C}$ & $189(69.5 \%)$ & $64(29.2 \%)$ & 1.00 & $<0.0001$ \\
\hline & $\mathrm{C} / \mathrm{T}-\mathrm{T} / \mathrm{T}$ & $83(30.5 \%)$ & $155(70.8 \%)$ & $5.51(3.74-8.14)$ & \\
\hline \multirow[t]{2}{*}{ Recessive } & $\mathrm{C} / \mathrm{C}-\mathrm{C} / \mathrm{T}$ & 268 (98.5\%) & $212(96.8 \%)$ & 1.00 & 0.2 \\
\hline & $\mathrm{T} / \mathrm{T}$ & $4(1.5 \%)$ & $7(3.2 \%)$ & $2.21(0.64-7.66)$ & \\
\hline \multirow[t]{2}{*}{ Overdominant } & $\mathrm{C} / \mathrm{C}-\mathrm{T} / \mathrm{T}$ & $193(71 \%)$ & $71(32.4 \%)$ & 1.00 & $<0.0001$ \\
\hline & $\mathrm{C} / \mathrm{T}$ & $79(29 \%)$ & $148(67.6 \%)$ & 5.09 (3.46-7.49) & \\
\hline
\end{tabular}


Table 4: TLR4 allele frequency distribution in controls and PCOS

\begin{tabular}{llllll}
\hline & \multicolumn{2}{c}{ Control } & & \multicolumn{2}{c}{ Patients } \\
\cline { 2 - 3 } \cline { 5 - 6 } Allele & Number & Frequency & & Number & Frequency \\
\hline A & 440 & 0.81 & & 268 & 0.61 \\
G & 104 & 0.19 & & 170 & 0.39 \\
\hline
\end{tabular}

Table 5: TLR4 genotypic frequency distribution in controls and PCOS

\begin{tabular}{llllll}
\hline & \multicolumn{2}{c}{ Control } & & \multicolumn{2}{c}{ Patients } \\
\cline { 2 - 3 } \cline { 6 - 6 } Genotype & Number & Frequency & & Number & Frequency \\
\hline A/A & 173 & 0.64 & & 59 & 0.27 \\
A/G & 94 & 0.35 & & 150 & 0.68 \\
G/G & 5 & 0.02 & & 10 & 0.05 \\
\hline
\end{tabular}

Table 6: Odds risk estimation of the TLR4 genotype in PCOS compared with controls

\begin{tabular}{|c|c|c|c|c|c|}
\hline Model & Genotype & Control & Patients & OR $(95 \% \mathrm{Cl})$ & $p$-value \\
\hline \multirow[t]{3}{*}{ Codominant } & $\mathrm{A} / \mathrm{A}$ & $173(63.6 \%)$ & $59(26.9 \%)$ & 1.00 & $<0.0001$ \\
\hline & $A / G$ & $94(34.6 \%)$ & $150(68.5 \%)$ & $4.68(3.16-6.93)$ & \\
\hline & $\mathrm{G} / \mathrm{G}$ & $5(1.8 \%)$ & $10(4.6 \%)$ & $5.86(1.93-17.86)$ & \\
\hline \multirow[t]{2}{*}{ Dominant } & $\mathrm{A} / \mathrm{A}$ & $173(63.6 \%)$ & $59(26.9 \%)$ & 1.00 & $<0.0001$ \\
\hline & $A / G-G / G$ & 99 (36.4\%) & $160(73.1 \%)$ & $4.74(3.22-6.98)$ & \\
\hline \multirow[t]{2}{*}{ Recessive } & $\mathrm{A} / \mathrm{A}-\mathrm{A} / \mathrm{G}$ & $267(98.2 \%)$ & $209(95.4 \%)$ & 1.00 & 0.081 \\
\hline & $\mathrm{G} / \mathrm{G}$ & $5(1.8 \%)$ & $10(4.6 \%)$ & $2.56(0.86-7.59)$ & \\
\hline \multirow[t]{2}{*}{ Overdominant } & $A / A-G / G$ & $178(65.4 \%)$ & $69(31.5 \%)$ & 1.00 & $<0.0001$ \\
\hline & $A / G$ & $94(34.6 \%)$ & $150(68.5 \%)$ & $4.12(2.82-6.01)$ & \\
\hline
\end{tabular}

was also observed to be associated with high risk to PCOS (OR 5.09, 95\% CI 3.46-7.49, p<0.0001; Table 3).

The " $G$ " allele was found to be in higher frequency in PCOS compared with controls ( 0.39 vs 0.19 , respectively; Table 4).

Heterozygote CT was found to be predominant in PCOS (0.68) when compared with controls ( 0.35 ; Table 5$)$.

The AG genotype was found to be predominant in PCOS with 4.68-fold increased risk to PCOS when compared with wild-type genotype (CC; OR 4.68, 95\% CI 3.16-6.93, $\mathrm{p}<0.0001$ ) (Table 6). Homozygous variant was also observed to be associated with PCOS (OR 5.86, 95\% CI 1.93-17.86, p <0.0001). Dominant model (CT + TT) was also found to be associated with high risk to PCOS (OR 4.74, 95\% CI 3.22-6.98, p<0.0001; Table 3). Based on the recessive model, GG genotype did not show any statistical significance when compared with the combination of AA + AG genotype (OR 2.56, 95\% CI 0.86-7.59, $\mathrm{p}=0.081$ ). Overdominant model CT (compared with $\mathrm{CC}+\mathrm{TT}$ genotype) genotype was also observed to be associated with high risk to PCOS (OR 4.12, 95\% CI 2.82-6.01, $\mathrm{p}<0.0001$; Table 3).

\section{DISCUSSION}

The recognition of genes underlying complex traits is an exigent task, and there are an inadequate number of established genes that influence human complex diseases. ${ }^{16}$ In particular, a small number of genes concerned with complex diseases associated with immune response, such as inflammatory diseases and infectious diseases, have been identified. ${ }^{16}$ In 2015, large-scale genetic and functional studies brought us closer to understanding the underlying etiology of PCOS. In this study, we have analyzed two innate immune gene polymorphisms (CD14 and TLR4) among women with PCOS and in healthy controls and experienced their association with PCOS.

The present study has shown the " $\mathrm{T}$ " allele of CD14 $(-159 \mathrm{C}>\mathrm{T})$ was found to be in higher frequency in PCOS compared with controls ( 0.37 vs 0.16 respectively). Härtel et $\mathrm{al}^{17}$ demonstrated genotypic frequencies for CD14 $(-159 \mathrm{C}>\mathrm{T})$ of infants, and no significant differences were noted between preterm very low birth weight and term infants. Our study has shown that heterozygote CT of CD14 was found to be predominant in PCOS (0.68) when compared with controls (0.29). The result of the current study showed that CT genotype was found to be significant in PCOS when compared with controls. Homozygous variant was also observed to be associated with PCOS (OR 5.17, 95\% CI 1.46-18.23, p<0.0001). Dominant model (CT + TT) was also found to be associated with high risk to PCOS when compared with controls.

We have observed that the variant allele of TLR4 299A $>$ G tends to be more predominant in women with PCOS compared with healthy controls. The TLR4 is expressed in adipose tissue, and it is possible that activation of these receptors in adipocytes might be a key contributor to the inflammatory state of adipocytes. ${ }^{18,19}$ Genetic variations in the TLR4 have been exposed to influence obesity-related insulin resistance. ${ }^{20}$ Our study could not establish the significant result with recessive model. The GG genotype did not show any statistical significance in PCOS when compared with controls. The AG genotype was found to be predominant in PCOS with 4.68-fold increased risk to PCOS when compared with controls. Heterozygote $\mathrm{CT}$ was found to be predominant in PCOS (0.68) when compared with controls (0.35). 
Genetic variations of the CD14 and TLR4 gene may have a distinct role in certain disease states. However, some studies suggest that synonymous single nucleotide polymorphisms (SNPs) might be able to change the resulting phenotypes, for example, abnormal kinetics of protein translation that would result in the folding of the polypeptide chain in different final conformations and, consequently, different cellular functions. ${ }^{21,22}$

In conclusion, our data suggest that polymorphisms of the innate immune genes (CD14 and TLR4) have a higher impact on PCOS. Because these genes are interlinked with each other, further studies are required to gain insight on how SNPs in each of the genes alter the protein structure and interaction, resulting in perturbation of the delicate immunologic balance in PCOS.

\section{REFERENCES}

1. Conway GS, Honour JW, Jacobs HS. Heterogeneity of the polycystic ovary syndrome: clinical, endocrine and ultrasound features in 556 patients. Clin Endocrinol (Oxf) 1989 Apr;30(4):459-470.

2. Laven JS, Imani B, Eijkemans MJ, Fauser BC. New approach to polycystic ovary syndrome and other forms of anovulatory infertility. Obstet Gynecol Surv 2002 Nov;57(11):755-767.

3. BoomsmaCM, Eijkemans MJ,HughesEG, Visser GH,Fauser BC, Macklon NS. A meta-analysis of pregnancy outcomes in women with polycystic ovary syndrome. Hum Reprod Update 2006 Nov-Dec;12(6):673-683.

4. Maitra A, Pingle RR, Menon PS, Naik V, Gokral JS, Meherji PK. Dyslipidemia with particular regard to apolipoprotein profile in association with polycystic ovary syndrome: a study among Indian women. Int J Fertil Womens Med 2001 SepOct;46(5):271-277.

5. Legro RS, Gnatuk CL, Kunselman AR, Dunaif A. Changes in 3 glucose tolerance over time in women with polycystic ovary syndrome: a controlled study. J Clin Endocrinol Metab 2005 Jun;90(6):3236-3242.

6. Deepika MLN, Ranjith K, Usha Rani V, Ishaq M, Jahan P. Familial background of complex diseases in PCOS probands of South Indian population. Asian J Epidemiol 2012;5(2) 50-55.

7. Yun JH, Choi JW, Lee KJ, Shin JS, Baek KH. The promoter $-1031(\mathrm{~T} / \mathrm{C})$ polymorphism in tumor necrosis factor-alpha associated with polycystic ovary syndrome. Reprod Biol Endocrinol 2011 Oct;9:131.

8. Escobar-Morreale HF, Luque-Ramírez M, González F. Circulating inflammatory markers in polycystic ovary syndrome: a systematic review and metaanalysis. Fertil Steril 2011 Mar;95(3):1048-1058.
9. Escobar-Morreale HF, Luque-Ramírez M, San Millán JL. The molecular-genetic basis of functional hyperandrogenism and the polycystic ovary syndrome. Endocr Rev 2005 Apr;26(2):251-282.

10. Wang T, Shen Y, Chen L, Guo S, Jia L, Yang T, Wen JAF. The $-159 \mathrm{C} / \mathrm{T}$ polymorphism in the CD14 gene and tuberculosis risk: a meta-analysis. Int J Med Sci 2013;10(11)1524-1529.

11. Calandra T, Roger T. Macrophage migration inhibitory factor: a regulator of innate immunity. Nat Rev Immunol 2003 Oct;3(10):791-800.

12. Akira S. Toll-like receptor signaling. J Biol Chem 2003 Oct;278(40):38105-38108.

13. Fei BY, Lv HX, Yang JM, Ye ZY. Association of MIF-173 gene polymorphism with inflammatory bowel disease in Chinese Han population. Cytokine 2008 Jan;41(1):44-47.

14. Karhukorpi J, Yan Y, Niemela S, Valtonen Koistinen P, Joensuu T, Saikku P, Karttunen R. Effect of CD14 promoter polymorphism and $H$. pylori infection and its clinical outcomes on circulating CD14. Clin Exp Immunol 2002 May;128(2):326-332.

15. Morange PE, Tiret L, Saut N, Luc G, Arveiler D, Ferrieres J, Amouyel P, Evans A, Ducimetiere P, Cambien F, et al. TLR4/ Asp299Gly, CD14/C-260T, plasma levels of the soluble receptor CD14 and the risk of coronary heart disease. Eur J Human Gene 2004 Dec;12(12):1041-1049.

16. Rihet P. Innate immunity genes as candidate genes: searching for relevant natural polymorphisms in databases and assessing family-based association of polymorphisms with human diseases. Methods Mol Biol 2008;415:17-48.

17. Härtel CH, Finas D, Ahrens P, Kattner E, Schaible TH, Müller D, Segerer H, Albrecht K, Möller J, Diedrich K, et al., For the Genetic Factors in Neonatology Study Group. Polymorphisms of genes involved in innate immunity: association with preterm delivery. Mol Hum Reprod 2004 Dec;10(12):911-915.

18. Bès-Houtmann S, Roche R, Hoareau L, Gonthier MP, Festy F, Caillens H, Gasque P, Lefebvre d'Hellencourt C, Cesari M. Presence of functional TLR2 and TLR4 on human adipocytes. Histochem Cell Biol 2007 Feb;127(2):131-137.

19. Kopp A, Buechler C, Neumeier M, Weigert J, Aslanidis C, Schölmerich J, Schäffle A. Innate immunity and adipocyte function: ligand-specific activation of multiple toll-like receptors modulates cytokine, adipokine, and chemokine secretion in adipocytes. Obesity (Silver Spring) 2009 Apr;17(4):648-656.

20. Steinhardt AP, Aranguren F, Tellechea ML, Gómez Rosso LA, Brites FD, Martínez-Larrad MT, Serrano-Ríos M, Frechtel GD, Taverna MJ. A functional nonsynonymous toll-like receptor 4 gene polymorphism is associated with metabolic syndrome, surrogates of insulin resistance, and syndromes of lipid accumulation. Metabolism 2010 May;59(5):711-717.

21. Komar AA. Genetics SNPs, silent but not invisible. Science 2007 Jan;315(5811):466-467.

22. Sauna ZE, Kimchi-Sarfaty C. Understanding the contribution of synonymous mutations to human disease. Nat Rev Genet 2011 Aug;12(10):683-691. 